\title{
A Comparative Study of Dexmedetomidine and Fentanyl on Airway Reflexes and Hemodynamic Responses to Tracheal Extubation in Nasal Surgeries
}

\author{
Saurabh Misra', Rajeev Tiwari', Shivendu Shekhar Ojha ${ }^{2}$ \\ ${ }^{1}$ Assistant professor, Varun Arjun Medical College, Shahjahnpur, India, ${ }^{2}$ Assistant Professor, MLN Medical College, Prayagraj, India.
}

\section{Abstract}

Background: Extubation at light levels of anesthesia or sedation can stimulate reflex responses via tracheal and laryngeal irritation. The present study was conducted to compare dexmedetomidine and fentanyl on airway reflexes and hemodynamic responses to tracheal extubation in nasal surgeries. Subjects and Methods: The present study was conducted on 60 patients of ASA grade I and Grade II of both genders. Patients were divided into 2 groups of 30 each. Group I were dexmedetomidine $0.5 \mu \mathrm{g} / \mathrm{kg}$ in $100 \mathrm{~mL}$ of isotonic saline and group II patients received fentanyl $1 \mu \mathrm{g} / \mathrm{kg}$ in $100 \mathrm{~mL}$ of isotonic saline intravenously. Parameters such as duration of surgery and duration of anesthesia (minutes) were recorded. Extubation time, awakening time and orientation time was recorded. Results: The ASA grade I was seen in 20 in group I and 14 in group II, ASA grade II was seen in 10 in group I and 16 I group II. Group I comprised of 14 males and 16 females, group II had 17 males and 13 females. Mean duration of surgery in group I was 172.4 minutes and in group II was 174.6 minutes in group II. Mean duration of anesthesia was 194.2 minutes in group I and 198.6 minutes in group II. The difference was non- significant (P>0.05). The mean extubation time in group I was 7.2 minutes and 5.6 minutes in group II, awakening time was 10.2 minutes in group I and 10.8 minutes in group II and orientation time was 14.3 minutes in group I and 15.2 minutes in group II. Conclusion: Authors found that dexmedetomidine $0.5 \mu \mathrm{g} / \mathrm{kg}$ IV, administered before extubation, was more effective in attenuating airway reflex responses to tracheal extubation as compared with fentanyl $1 \mu \mathrm{g} / \mathrm{kg}$ IV.

Keywords: Dexmedetomidine, tracheal extubation, nasal surgery.

Corresponding Author: Dr. Rajeev Tiwari, Assistant Professor, Varun Arjun Medical College, Shahjahnpur, India.

Received: May 2020

Accepted: May 2020

\section{Introduction}

Tracheal extubation is the discontinuation of an artificial airway when the indications for its placement like airway obstruction, protection of airway, suctioning, ventilatory failure and hypoxemia no longer exist. ${ }^{[1]}$ For a smooth extubation, there should be no straining, movement, coughing, breath holding or laryngospasm. ${ }^{[2]}$ Extubation at light levels of anesthesia or sedation can stimulate reflex responses via tracheal and laryngeal irritation. ${ }^{[3,4]}$

When a patient is deeply anesthetized, tracheal extubation during rhinoplasty can be difficult because of an obstructed nasal airway, blood and secretions in the pharynx, and difficulty performing manual ventilation by face mask owing to the newly reconstructed nose. ${ }^{[5]}$ However, when a patient is lightly anesthetized, extubation can stimulate reflex responses via tracheal and laryngeal irritation. Complications of extubation such as breath holding, laryngospasm, and pulmonary edema might occur. ${ }^{[6]}$

Fentanyl, a synthetic opioid, has been reported to reduce the prevalence of coughing during and after extubation and to suppress the sneezing reflex after abdominal hysterectomy and periocular injections. Fentanyl has also been reported to attenuate the cardiovascular responses to tracheal extubation in elective gynecologic surgery. ${ }^{[7]}$ Dexmedetomidine, an $\alpha 2$ adrenoreceptor agonist with a distribution half life of approximately 6 minutes has been successfully used for attenuating the stress response to laryngoscopy. Currently, dexmedetomidine is indicated for intensive care unit sedation in mechanically ventilated patients and for sedation of non intubated patients before or during surgical and other procedures. ${ }^{[8]}$ The present study was conducted to compare dexmedetomidine and fentanyl on airway reflexes and hemodynamic responses to tracheal extubation in nasal surgeries.

\section{Subjects and Methods}

The present study was conducted in the department of Anesthesiology on 60 patients of ASA grade I and Grade II of both genders admitted for nasal surgeries. All patients were informed regarding the study and written consent was obtained. Ethical approval was obtained from institutional ethical committee.

Data such as name age, gender etc. was recorded. Patients were divided into 2 groups of 30 each. Group I were 
dexmedetomidine $0.5 \mu \mathrm{g} / \mathrm{kg}$ in $100 \mathrm{~mL}$ of isotonic saline and group II patients received fentanyl $1 \mu \mathrm{g} / \mathrm{kg}$ in $100 \mathrm{~mL}$ of isotonic saline intravenously. Parameters such as duration of surgery and duration of anesthesia (minutes) were recorded. Extubation time, awakening time and orientation time was recorded. Results thus obtained were subjected to statistical analysis. $\mathrm{P}$ value less than 0.05 was considered significant $(\mathrm{p}<0.05)$.

\section{Results}

Table 1: Distribution of patients

\begin{tabular}{|l|l|l|}
\hline Groups & Group I & Group II \\
\hline Agent & $\begin{array}{l}\text { Dexmedetomidine } 0.5 \mu \mathrm{g} / \mathrm{kg} \\
\text { in } 100 \mathrm{~mL} \text { of isotonic saline }\end{array}$ & $\begin{array}{l}\text { Fentanyl } 1 \mu \mathrm{g} / \mathrm{kg} \text { in } 100 \\
\mathrm{~mL} \text { of isotonic saline }\end{array}$ \\
\hline Number & 30 & 30 \\
\hline
\end{tabular}

[Table 1] shows that group I received dexmedetomidine 0.5 $\mu \mathrm{g} / \mathrm{kg}$ in $100 \mathrm{~mL}$ of isotonic saline and group II patients received fentanyl $1 \mu \mathrm{g} / \mathrm{kg}$ in $100 \mathrm{~mL}$ of isotonic saline intravenously.

Table 2: Comparison of parameters
\begin{tabular}{|l|l|l|l|}
\hline Parameters & Group I & Group II & P value \\
\hline ASA grade & & & \\
\hline I & 20 & 14 & 0.17 \\
\hline II & 10 & 16 & \\
\hline Gender & & & 0.11 \\
\hline Male & 14 & 17 & 0.94 \\
\hline Female & 16 & 13 & 0.81 \\
\hline $\begin{array}{l}\text { Duration of surgery } \\
\text { (minutes) }\end{array}$ & 172.4 & 174.6 & \\
\hline $\begin{array}{l}\text { Duration of anesthesia } \\
\text { (minutes) }\end{array}$ & 194.2 & 198.6 & \\
\hline
\end{tabular}

\section{Table 3: Comparison of extubation, awakening and orientation} times

\begin{tabular}{|l|l|l|l|}
\hline $\begin{array}{l}\text { Parameters } \\
\text { (mins) }\end{array}$ & Group I & Group II & P value \\
\hline Extubation time & 7.2 & 5.6 & 0.14 \\
\hline Awakening time & 10.2 & 10.8 & 0.23 \\
\hline Orientation time & 14.3 & 15.2 & 0.38 \\
\hline
\end{tabular}

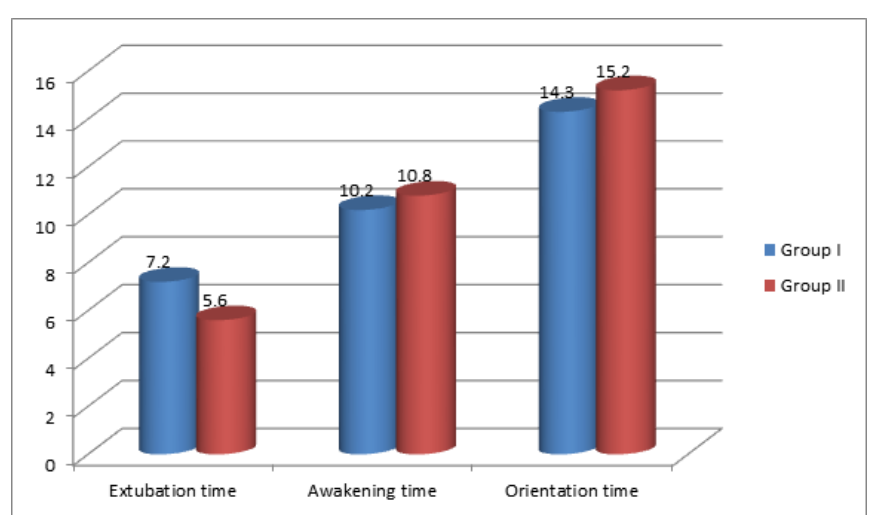

Figure 1: Comparison of extubation, awakening and orientation times

[Table 2] shows ASA grade I was seen in 20 in group I and 14 in group II, ASA grade II was seen in 10 in group I and 16 I group II. Group I comprised of 14 males and 16 females, group II had 17 males and 13 females. Mean duration of surgery in group I was 172.4 minutes and in group II was
174.6 minutes in group II. Mean duration of anesthesia was 194.2 minutes in group I and 198.6 minutes in group II. The difference was non- significant $(\mathrm{P}>0.05)$.

[Table $3 \&$ Figure 1] shows that mean extubation time in group I was 7.2 minutes and 5.6 minutes in group II, awakening time was 10.2 minutes in group $\mathrm{I}$ and 10.8 minutes in group II and orientation time was 14.3 minutes in group I and 15.2 minutes in group II. The difference was non- significant $(\mathrm{P}>0.05)$.

\section{Discussion}

Extubation can be associated with several complications like coughing and respiratory and hemodynamic alterations. These changes are usually transient and well tolerated by most patients, but may be deleterious in certain subgroups of patients. Dexmedetomidine has been successfully used to attenuate the hemodynamic responses to tracheal intubation. ${ }^{[9]}$ The present study was conducted to compare dexmedetomidine and fentanyl on airway reflexes and hemodynamic responses to tracheal extubation in nasal surgeries.

In present study, group I received dexmedetomidine 0.5 $\mu \mathrm{g} / \mathrm{kg}$ in $100 \mathrm{~mL}$ of isotonic saline and group II patients received fentanyl $1 \mu \mathrm{g} / \mathrm{kg}$ in $100 \mathrm{~mL}$ of isotonic saline intravenously. Aksu et al, ${ }^{[10]}$ included 40 patients. There were no clinically significant decreases in HR, SBP, DBP, or $\mathrm{SpO} 2$ after extubation with dexmedetomidine or fentanyl. In the dexmedetomidine group, $\mathrm{HR}$ was not significantly increased after extubation; however, in the fentanyl group, HR was significantly increased compared with the preextubation values. HR was significantly higher in the fentanyl group compared with the dexmedetomidine group at 1, 5, and 10 minutes after extubation. Compared with preextubation values, SBP was significantly increased at 1 and 5 minutes after extubation in the dexmedetomidine group and at 1,5 , and 10 minutes after extubation in the fentanyl group. The postoperative sedation scores and the extubation, awakening, and orientation times were not significantly different between the 2 groups. In the dexmedetomidine group, bradycardia (HR <45 beats/min) was observed in 2 patients and emesis was observed in 2 patients. In the fentanyl group, emesis was observed in 3 patients, bradycardia in 2 patients, vomiting in 1 patient, and shivering in 1 patient; vertigo was reported in 1 patient. There were no significant differences in the prevalence of adverse events between the 2 groups.

In present study, ASA grade I was seen in 20 in group I and 14 in group II, ASA grade II was seen in 10 in group I and 16 I group II. Group I comprised of 14 males and 16 females, group II had 17 males and 13 females. Mean duration of surgery in group I was 172.4 minutes and in group II was 174.6 minutes in group II. Mean duration of anesthesia was 194.2 minutes in group I and 198.6 minutes in group II.

Bindu et al, ${ }^{[1]}$ included fifty patients aged 2045 years, scheduled for elective general surgical, urological and gynecological surgeries. Group $\mathrm{A}$ and $\mathrm{B}$, received an intravenous infusion of dexmedetomidine $0.75 \mathrm{mcg} / \mathrm{kg}$ or placebo respectively, over 15 minutes before anticipated time of end of surgery, in a double blind manner. Anesthesia techniques were standardized. Heart rate, systolic, diastolic, 
mean arterial pressures were recorded while starting injection, at $1,3,5,10,15$ minutes after starting injection, during extubation, at 1,3,5 minutes after extubation, and thereafter every 5 minutes for 30 minutes. Quality of extubation was evaluated on a 5 point scale and postoperative sedation on a 6 point scale. Any event of laryngospasm, bronchospasm, desaturation, respiratory depression, vomiting, hypotension, undue sedation was noted. Heart rate, systolic, diastolic, mean arterial pressures were significantly higher in group B. Extubation quality score of majority of patients was 2 in group A and 3 in group B. Sedation score of most patients was 3 in group A and 2 in group B. Bradycardia and hypotension incidences were higher in group A. One patient in group A, two patients in group B had vomiting. No patient had any other side effects. We found that mean extubation time in group I was 7.2 minutes and 5.6 minutes in group II, awakening time was 10.2 minutes in group I and 10.8 minutes in group II and orientation time was 14.3 minutes in group I and 15.2 minutes in group II. Nishina et al, ${ }^{[12]}$ compared the effects of fentanyl 1 and $2 \mu \mathrm{g} / \mathrm{kg}$ IV with those of a control group (placebo) on hemodynamic changes during tracheal extubation and emergence from anesthesia in 60 patients who underwent elective gynecologic surgery. Although those authors recommended the $2-\mu \mathrm{g} / \mathrm{kg}$ dose - because while the number of patients who experienced coughs or strains was similar among the 3 groups, the severity of these symptoms was attenuated in the fentanyl group that received the higher dose-they reported that the $1-$ and $2-\mu \mathrm{g} / \mathrm{kg}$ doses were associated with a significantly reduced HR $(\mathrm{P}<0.05)$ but found no significant difference in the prevalence of cough compared with placebo.

\section{Conclusion}

Authors found that dexmedetomidine $0.5 \mu \mathrm{g} / \mathrm{kg}$ IV, administered before extubation, was more effective in attenuating airway reflex responses to tracheal extubation as compared with fentanyl $1 \mu \mathrm{g} / \mathrm{kg} \mathrm{IV}$.

\section{References}

1. Baraka A. Intravenous lidocaine controls extubation laryngospasm in children. Anesth Analg. 1978;57:506-507.

2. Rex MA. A review of the structural and functional basis of laryngospasm and a discussion of the nerve pathways involved in the reflex and its clinical significance in man and animals. $\mathrm{Br} \mathrm{J}$ Anaesth. 1970;42:891-899.

3. Cranfield KA, Bromley LM. Minimum alveolar concentration of desflurane for tracheal extubation in deeply anaesthetized, unpremedicated children. Br J Anaesth. 1997;78:370-371.

4. Hartley M, Vaughan RS. Problems associated with tracheal extubation. Br J Anaesth. 1993;71:561-568.

5. Bidwai AV, Bidwai VA, Rogers CR, Stanley TH. Blood-pressure and pulse-rate responses to endotracheal extubation with and without prior injection of lidocaine. Anesthesiology. 1979;51:171-173.

6. Koga K, Asai T, Vaughan RS, Latto IP. Respiratory complications associated with tracheal extubation. Timing of tracheal extubation and use of the laryngeal mask during emergence from anaesthesia. Anaesthesia. 1998;53:540-544.

7. Venn RM, Bradshaw CJ, Spencer R, et al. Preliminary UK experience of dexmedetomidine, a novel agent for postoperative sedation in the intensive care unit. Anaesthesia. 1999;54: 1136-1142.

8. Zub D, Berkenbosch JW, Tobias JD. Preliminary experience with oral dexmedetomidine for procedural and anesthetic premedication. Paediat Anaesth. 2005; 15:932-938.

9. Ibacache M, Muñoz HR, Brandes V, Morales AL. Single-dose dexmedetomidine reduces agitation after sevoflurane anesthesia in children. Anesth Analg. 2004;98:60-63.

10. Aksu R, Akin A, Biçer C, Esmaoğlu A, Tosun Z, Boyaci A. Comparison of the effects of dexmedetomidine versus fentanyl on airway reflexes and hemodynamic responses to tracheal extubation during rhinoplasty: A double-blind, randomized, controlled study. Current therapeutic research. 2009 Jun 1;70(3):209-20

11. Bindu B, Pasupuleti S, Gowd UP, Gorre V, Murthy RR, Laxmi MB. A double blind, randomized, controlled trial to study the effect of dexmedetomidine on hemodynamic and recovery responses during tracheal extubation. J Anaesthesiol Clin Pharmacol 2013;29:162-7.

12. Nishina K, Mikawa K, Maekawa N, Obara H. Fentanyl attenuates cardiovascular responses to tracheal extubation. Acta Anaesthesiol Scand. 1995;39:85-89.

Copyright: (C) the author(s), 2020. It is an open-access article distributed under the terms of the Creative Commons Attribution License (CC BY 4.0), which permits authors to retain ownership of the copyright for their content, and allow anyone to download, reuse, reprint, modify, distribute and/or copy the content as long as the original authors and source are cited.

How to cite this article: Misra S, Tiwari R, Ojha SS. A Comparative Study of Dexmedetomidine and Fentanyl on Airway Reflexes and Hemodynamic Responses to Tracheal Extubation in Nasal Surgeries. Acad. Anesthesiol. Int. 2020;5(1):143-145.

DOI: dx.doi.org/10.21276/aan.2020.5.1.28

Source of Support: Nil, Conflict of Interest: None declared. 